\title{
Caracterización de cepas de Escherichia coli productor de Shigatoxina (STEC) aisladas desde cerdos y bovinos sanos, faenados en la Región Metropolitana
}

\author{
Roberto Vidal $^{1}$, Laura Corvalán ${ }^{2}$, Solange Vivanco ${ }^{2}$ \\ ${ }^{1}$ Jefe Laboratorio de Escherichia coli Enteropatógeno, Programa de Microbiología y Micología de la \\ Facultad de Medicina de la Universidad de Chile. Email: rvidal@med.uchile.cl \\ ${ }^{2}$ Tesistas Facultad de Medicina Veterinaria
}

\begin{abstract}
Resumen
Escherichia coli productor de Shigatoxinas (STEC) es un patógeno zoonótico emergente de gran importancia en las enfermedades transmitidas por alimentos (ETAs). En humanos STEC puede producir cuadros de diarrea aguda, disentería, o bien, evolucionar a su complicación extra-intestinal más grave, el Síndrome Hemolítico Urémico (SHU). El reservorio más importante para las infecciones humanas son los bovinos y porcinos. Estudios previos realizados en Chile (1997) describen que el 28,7\% de los bovinos y el 68,3\% de los cerdos estudiados estaban colonizados por STEC. El marcado aumento en el consumo de carne en Chile (81 kg/año por persona) es una condición que eleva el riesgo de infección por STEC. Por esta razón nuestro laboratorio investigó la frecuencia de portación intestinal de STEC en animales faenados de ambas especies de producción ( 385 cerdos/759 bovinos), caracterizando el patrón toxigénico de los aislados (stxl/stx2), la presencia de genes de virulencia (eae, ent, efal, hlya, lpf, iha y saa) y el serogrupo (O157/No-O157). Se aislaron cepas de STEC en un 6\% de cerdos y un 13,5\% de bovinos. STEC aisladas de cerdos no presentaron ninguno de los genes de virulencia descritos en aislados clínicos, sin embargo, éstos sí fueron detectados en cepas asiladas de bovinos (lpf, efal, iha y saa). Lo patrones toxigénicos de STEC de bovinos (stxl-stx2 y stx2) fueron diferentes a los observados en los aislados de cerdos (stx2). El estudio de campo pulsado muestra que en ambos grupos de animales no existen clones únicos circulantes. En conclusión se recomienda continuar investigando la presencia de STEC en productos cárneos derivados de bovinos que se expenden en Chile.
\end{abstract}

Financiamiento: Proyectos Fondecyt $N^{\circ} 1061088-1110260$. 